\title{
PENGARUH KECEPATAN CETAKAN HORIZONTAL CENTRIFUGAL CASTING TERHADAP KEKERASAN DAN STRUKTUR MIKRO PADA RADIAL SLIDING BEARING BABBITT-BAJA KARBON
}

\author{
Alaya Fadllu Hadi Mukhammad ${ }^{1}$, Bambang Setyoko ${ }^{2}$
}

\begin{abstract}
ABSTRAK
Kecepatan Cetakan meruakan salah satu parameter utama dalam pembuatan Radial Sliding Bearing (RSB)menggunakan metode horizontal centrifugal casting. Kecepatan cetakan akan mempengaruhi kualitas hasil pengecoran yang ditunjukkan dengan sedikitnya cacat pengecoran yang dihasilkan. Selain cacat pengecoran kualitas RSB juga dipengaruhi properties dari babbitt yang dihasilkan dari pengecoran berupa kekerasan, ketahanan aus dan ikatan interface babbitt-shell. Penelitian ini bertujuan mengetahui pengaruh kecepatan putaran cetakan (shell) dengan variasi 500, dan 1000 rpm terhadap kekerasan dan struktur mikro pada babbitt dan shell. Bahan yang digunakan adalah pipa steam (baja karbon) dan babbitt (Tin). Hasil pengujian kekerasan dan struktur mikro menunjukkan kecepatan putaran cetakan tidak berpengaruh secara signifikan dan proses tinning shell, pemanasan awal dan pengecoran babbitt tidak memberikan perubahan struktur mikro pada logam shell.
\end{abstract}

Kata Kunci: RSB, centrifugal casting, kekerasan, struktur mikro

\section{PENDAHULUAN}

Radial sliding bearing (Gambar 1) adalah komponen utama rotating machinery yang berfungsi sebagai bantalan shaft dalam menahan gaya radial. Pada dasarnya $R S B$ terdiri dari dua komponen utama yaitu shell (substrate) dan babbitt (Mukhammad dan Setyoko, 2016(a)). Paduan berbahan dasar Tin dan lead paling populer digunakan sebagai bahan $R S B$ (Leszczy'nska-Madej, dan Madej, 2013), sedangkan shell biasanya terbuat dari besi cor, baja karbon, dan paduan tembaga (Mukhammad dan Setyoko, 2016(b)). Walaupun Babbitt-baja banyak digunakan sebagai bahan sliding bearings, akan tetapi untuk menghasilkan slidingbearing berkualitas memerlukan banyak usaha dikarenakan ikatan interface antara shell dan babbitt yang lemah (Fathy, 2018) Proses Fluxing dan Tinning biasa digunakan unuk meningkatkan bonding antara shell dengan babbitt (Liaw dkk, 1990)

Metode proses pembuatan $R S B$ turbin akan mempengaruhi kekuatan ikatan dan struktur mikro sehingga mempengaruhi ketahanan dan kemampuan $R S B$ (Diouf dan Jones, 2010). Ada

\footnotetext{
${ }^{1}$ Program Sarjana Terapan Rekayaya Perancangan Mekanik, Sekolah Vokasi, Universitas Diponegoro Semarang

${ }^{2}$ Program Sarjana Terapan Rekayaya Perancangan Mekanik, Sekolah Vokasi, Universitas Diponegoro Semarang
} 
tiga metode yang umum digunakan untuk mengikat babbit dengan shell yaitu metode gravity casting, centrifugal casting dan thermal spray.

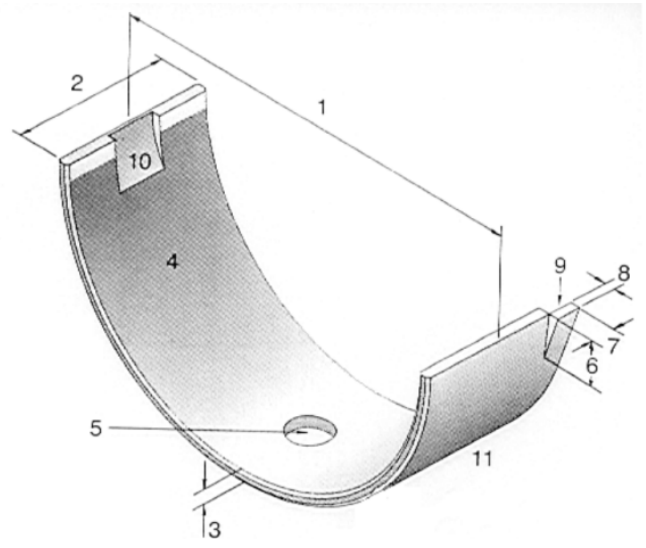

Keterangan :
1. Diameter luar
6. Panjang lip
2. Panjang bearing
7. Lebar lip
3. Tebal bearing
8. Kedalaman lip
4. Overplate
9. Bentuk lip
5. Lubang oli
10. Alur oli

Gambar 1. Bentuk dasar RSB

Tabel 1. Komposisi kimia babbitt berbasis Tin

\begin{tabular}{cccccc}
\hline Unsur & Tin & Antimony & Lead & Copper & Others \\
\hline Standar & $88-90$ & $7-8$ & 0,35 & $3-4$ & Ballance \\
ASTM B23 & & & & & \\
\hline
\end{tabular}

Metode gravity casting sudah digunakan oleh industri lokal untuk memproduksi $R S B$ turbin tetapi kualitasnya rendah. Gravity casting ini memiliki banyak kekurangan diantaranya adalah lemahnya bonding interface babbit dengan shell metal karena adanya porositas sehingga menyebabkan delaminasi. Perbaikan metode proses pengecoran terus dilakukan untuk menghasilkan produk coran yang kualitas, salah satu metode pengecoran yang peneliti lakukan adalah metode pengecoran sentrifugal. Metode ini memanfaatkan putaran untuk menghasilkan gaya sentrifugal.

Gaya sentrifugal yang dihasilkan oleh putaran cetakan akan menyebabkan logam cair yang dituang terdorong menjauhi sumbu putar dan menuju jari-jari terjauh cetakan dan 
menghasilkan pengisian rongga cetakan lebih sempurna (Jorstad, 1993). Diouf dan Jones, (2010) telah melakukan penelitian mengenai pengaruh parameter centrifugal casting (kecepatan putaran, laju penuangan dan laju pendinginan) pada $R S B$ babbit dengan material besi cor. Hasil penelitian menunjukkan bahwa microstructure pada interface ikatan sangat dipengaruhi laju pendinginan. Semakin tinggi laju pendinginan maka struktur mikro yang dihasilkan semakin bagus, sedangkan kecepatan putar dan laju penuangan memiliki pengaruh kecil terhadap kekuatan bonding, semakin tinggi kecepatandan laju penuangan menghasilkan ikatan yang sedikit lebih bagus.

\section{METODE PENELITIAN}

Shell terbuat dari pipa baja steam dengan ukuran Diameter luar $60 \mathrm{~mm}$ dan diameter dalam $45 \mathrm{~mm}$ dan panjang $40 \mathrm{~mm}$, Pipa baja steam kemudian dibubut diameter luar dan dalamnya menjadi $59 \mathrm{~mm}$ dan $50 \mathrm{~mm}$. Pipa baja steam dan babbitt dengan kode PPN III diperoleh dari pasar komersial.

Proses tinning shell dilakukan dengan cara memanaskan mencapai temperatur $200 \mathrm{oC}$ dan suspensi tinning diusapkan menggunakan kuas pada permukaan dalam sampai merata. Proses centrifugal casting dilakukan dengan menggunakan mesin bubut, dan diputar dengan kecepatan 500 dan 1000 rpm. Pengaturan putaran menggunakan inverter. Shell yang telah siap kemudian dimasukkan ke dalam cetakan. Babbitt dipanaskan mencapai temperatur $400{ }^{\circ} \mathrm{C}$, dan dituangkan ke cetakan yang berputar melalui corong yang telah dipanaskan sampai cairan babbitt tumpah keluar dari cetakan. Pendinginan dilakukan secara alami yaitu dengan udara lingkungan.

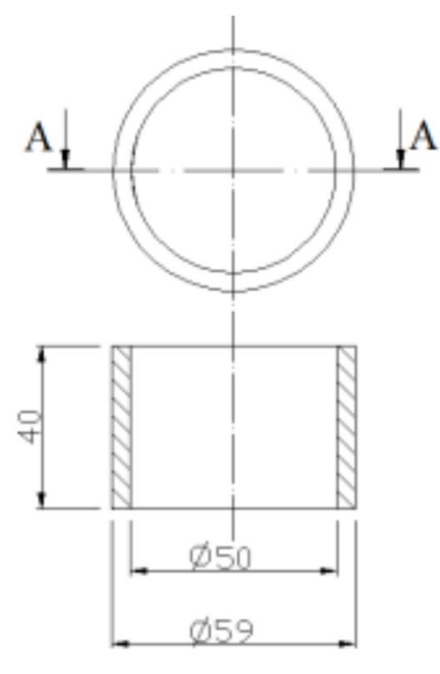

POTONGAN A-A

Gambar 2. Bentuk dan Dimensi Shell RSB 
Karakterisasi logam dilakukan pada logam babbitt dan shell. baja bahan shell menggunakan metode spectrometer. Pengujian kekerasan menggunakan metode kekerasan Vickers. Pengambilan titik-titik pengujian dilakukan dari batas antara babbitt dan shell. Setiap titik berjarak $1 \mathrm{~mm}$.

\section{HASIL DAN PEMBAHASAN}

\section{Pengujian Komposisi Kimia}

Pengujian Komposisi kimia shell menggunakan spektro diperoleh prosentase komposisi kimia seperti pada Tabel 2.

Tabel 2. Komposisi Kimia Pipa Steam bahan Shell

\begin{tabular}{ccccccccc}
\hline Unsur & $\mathrm{Fe}$ & $\mathrm{Si}$ & $\mathrm{C}$ & $\mathrm{Mn}$ & $\mathrm{Cr}$ & $\mathrm{Cu}$ & $\mathrm{Ni}$ & $\mathrm{S}$ \\
\hline Prosentase & 99,06 & 0,21 & 0,23 & 0,40 & 0,12 & 0,11 & 0,01 & 0,01 \\
\hline
\end{tabular}

\section{Pengujian Dimensional}

Pengujian Dimensional dilakukan dengan pengukuran dimensi hasil coran centrifugal casting. Hasil pengecoran putaran cetakan $500 \mathrm{rpm}$ dan $1000 \mathrm{rpm}$ menunjukkan bahwa semua bagian shell tertutupi lapisan babbitt dengan ketebalan rata-rata yang berbeda yaitu 2,3 mm dan 6 mm (Mukhammad dan Setyoko, 2016).

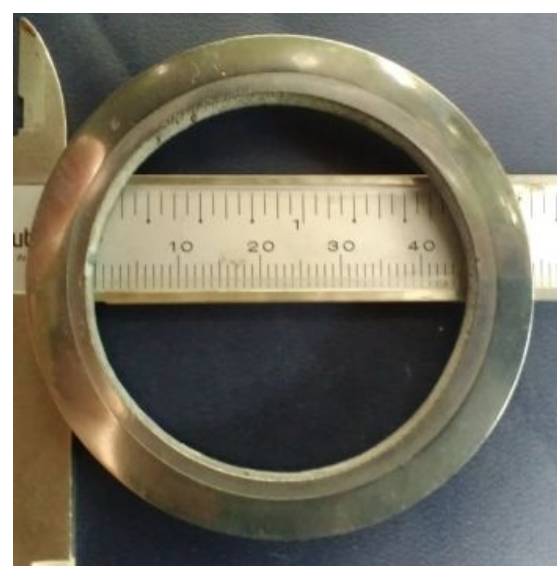

(a)

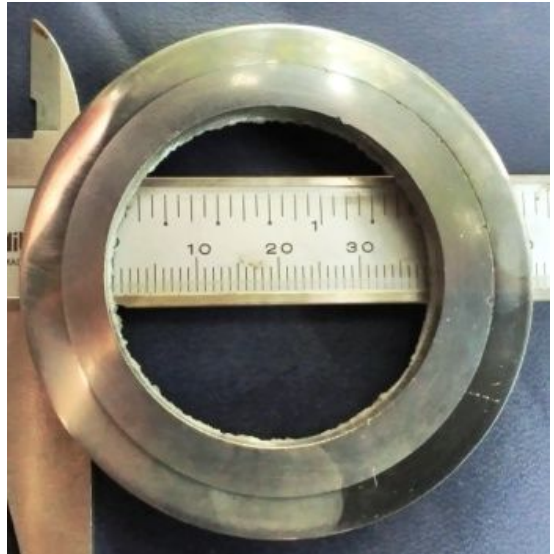

(b)

Gambar 4. RSB centrifugal casting (a) $500 \mathrm{rpm}$, (b) $1000 \mathrm{rpm}$ 


\section{Pengujian Kekerasan dan Struktur Mikro}

Pengujian kekerasan menggunakan metode uji Vickers dengan pembebanan 200 gf. Pengujian vickers dilakukan pada shell dan babbitt.

Tabel 3. HasilPengujian Kekerasan dan struktur mikro CSB

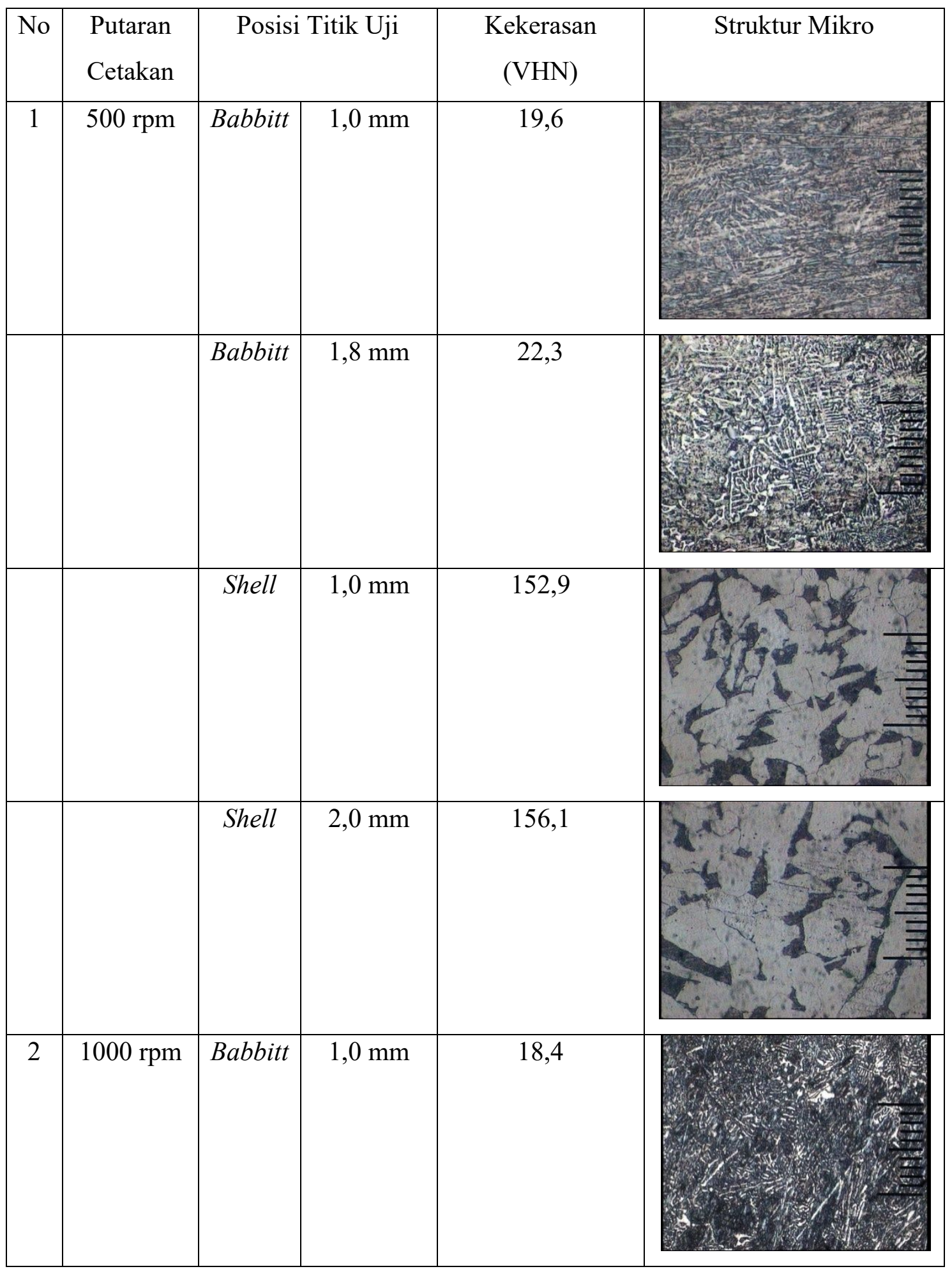




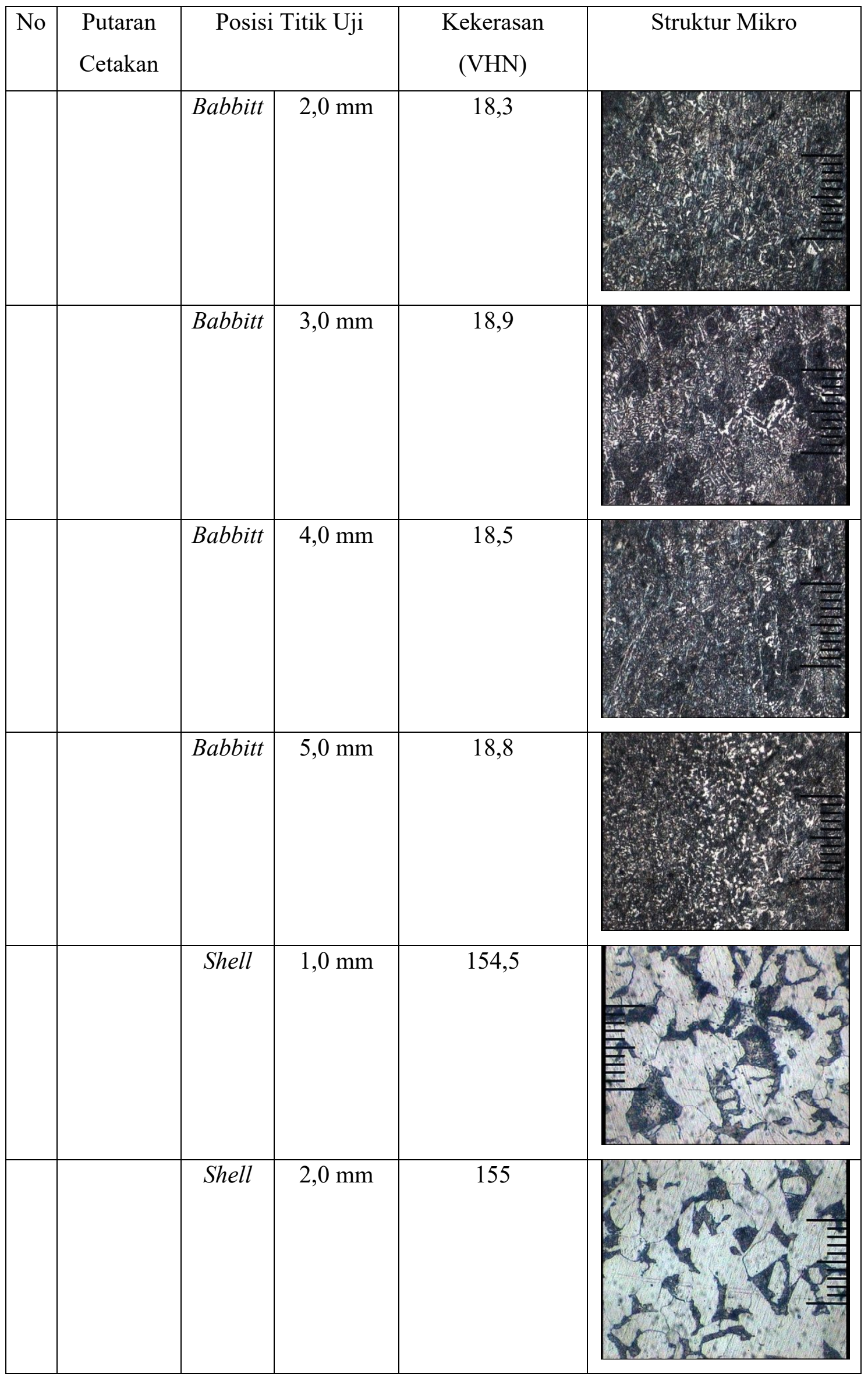


Hasil pengujian struktur mikro pada daerah shell dengan kecepatan putan cetakan 500 dan 1000 rpm didominasi struktur ferrite (putih) dan pearlite (hitam belang) merata dari interface babbit ke permukaan shell. Hal ini menunjukkan bahwa pemanasan awal sebelum pengecoran dan pengecoran babbit tidak mengubah properties dari pipa baja steam yang tergolong baja karbon rendah. Pengujian kekerasan juga menunjukkan bahwa tidak terjadi perubahan kekerasan yang signifikan. Fenomena tersebut sangatlah beralasan karena pemanasan awal dan pengecoran yang berkisar pada temperatur $400{ }^{\circ} \mathrm{C}$, jauh lebih rendah di bawah temperatur rekristalisasi baja karbon.

Pada material babbit pada kecepatan putaran 500 dan 1000 rpm menunjukkan fenomena dominasi struktur logam timah. Hasil pengujian kekerasan juga menunjukkan kekerasan babbit pada kecepatan putaran 500 dan 1000 rpm relatif stabil yaitu berkisar pada 18-22 VHN. Kekerasan babbit yang relatif stabil ini sesuai dengan tidak terjadinya perubahan struktur kristal antar lapisan dan minimnya porositas yang terjadi pada bagian interface antara babbit dan shell (Mukhammad dan Setyoko, 2016).

\section{KESIMPULAN}

1. Kecepatan putaran cetakan tidak berpengaruh secara signifikan terhadap struktur mikro dan kekerasan logam babbit dan shell.

2. Proses tinning shell, pemanasan awal dan pengecoran babbitt tidak memberikan perubahan struktur mikro pada logam shell.

\section{UCAPAN TERIMA KASIH}

Tim penulis mengucapkan terimakasih kepada Kementerian Riset, Teknologi dan Pendidikan Tinggi atas pendanaan penelitian ini melalui skema Riset Pengembangan dan Penerapan sumber dana selain APBN TA 2018 Universitas Diponegoro Semarang.

\section{DAFTAR PUSTAKA}

Diouf, P dan Jones. A.2010. Investigation of Bond Strength in Centrifugal Lining of Babbit on Cast Iron. Metalurgical and Material Transactions A. Vol 41 March

Jorstad. J.L.. Rasmussen. Wayne. M.. 1993. Aluminum Casting Technology. U.S.A: American Foundrymen's Society. Inc.

Leszczy'nska-Madej, B. Dan Madej, M. 2013. Effect of the heat treatment on the microstructure and properties of tin Babbitt. Kovove Mater. 51 
Liaw, P. K. . Gungor, M. N Logsdon,W.A. Ijiri,Y. Taszarek,B. J. Frohlich, S. 1990. Effect of Phase Morphologies on the Mechanical Properties of Babbitt-Bronze Composite Interfaces, Metallurgical Transactions A, Vol. 21, No. 2, pp. 529-538,

Mukhammad, A.F.H. dan Setyoko, Bambang. 2016(a). Studi Awal Pengaruh Alur Profil Shell Terhadap Cacat Pengecoran Radial Sliding Bearing Babbitt-Baja Karbon dengan Metode Horizontal Centrifugal casting. TRAKSI. Vol. 16 No. 1

Mukhammad, A.F.H. dan Setyoko, Bambang. 2016(b). Pengaruh Kecepatan Putaran Shell Terhadap Ketebalan dan Cacat Pengecoran Radial Sliding Bearing Babbitt-Baja Karbon dengan Metode Horizontal Centrifugal casting. TRAKSI. Vol. 16 No. 2

\section{PENULIS:}

\section{ALAYA FADLLU HADI MUKHAMMAD}

Program Sarjana Terapan Rekayaya Perancangan Mekanik, Sekolah Vokasi, Universitas Diponegoro Semarang

J1.Prof. H. Sudharto, SH - Tembalang, Semarang.

Email : alayad3tm@gmail.com

\section{BAMBANG SETYOKO}

Program Sarjana Terapan Rekayaya Perancangan Mekanik, Sekolah Vokasi, Universitas Diponegoro Semarang

Jl.Prof. H. Sudharto, SH - Tembalang, Semarang.

Email : bsetyoko@ymail.com 